\title{
Correction to: Improved Student Reasoning About Carbon-Transforming Processes Through Inquiry-Based Learning Activities Derived from an Empirically Validated Learning Progression
}

\author{
J. W. Schramm ${ }^{1} \cdot$ H. Jin ${ }^{2}$ • E. G. Keeling ${ }^{3} \cdot$ M. Johnson ${ }^{4} \cdot$ H. J. Shin ${ }^{5}$ \\ Published online: 12 September 2018 \\ (C) Springer Nature B.V. 2018
}

\section{Correction to: Research in Science Education https://doi.org/10.1007/s11165-016-9584-0}

The original version of this article unfortunately contained mistakes. The names of the authors were published incorrectly. The Publisher apologizes for the errors. Below are the corrections:

1) The name of the corresponding author "J. W. Schramm" was incorrectly captured as "Schramm JW." The name should be corrected to "J. W. Schramm"

2) The co-author's names were incorrectly captured as "H Jin • EG Keeling • M Johnson • HJ Shin". The names should be corrected to "H. Jin • E. G. Keeling • M. Johnson • H. J. Shin"

The original article has been corrected.

The online version of the original article can be found at https://oi.org/10.1007/s11165-016-9584-0

J. W. Schramm jschramm@goshen.edu

1 Department of Sustainability and Environmental Education, Merry Lea Environmental Learning Center of Goshen College Wolf Lake, Albion, IN, USA

2 Educational Testing Service, Princeton, NJ, USA

3 Biology Department, State University of New York-New Paltz, New Paltz, NY, USA

4 Marine Science Institute, University of California-Santa Barbara, Santa Barbara, CA, USA

5 Education Testing Service, Princeton, NJ, USA 